\title{
El Reel Videocurrículum como estrategia para el fomento del marketing profesional
}

\begin{abstract}
Ángela María Sánchez Sánchez-Manjavacasa, María Soledad Folgado Canellesb, Antonia Madueño Toribio ${ }^{c}$, Amparo Martín Moret ${ }^{d}$ y Luis Valero Taverner $^{\mathrm{e}}$

aprofesora ISEP CEU CV, angela_maria.sanchez@ciclosformativosceu.es, ${ }^{b}$ Profesora ISEP CEU CV, marisol.folgado@ciclosformativosceu.es, $\quad{ }^{c}$ Profesora ISEP CEU CV, antonia.madueno@ciclosformativosceu.es, $\quad{ }^{\mathrm{d} P r o f e s o r a} \quad$ ISEP CEU CV, amparo.martin3@ciclosformativosceu.es,_ ${ }^{e}$ Profesor ISEP CEU CV, luis.valero@ciclosformativosceu.es
\end{abstract}

\begin{abstract}
La realización del proyecto Reel-Videocurrículum combina en una misma pieza el recurso del Vídeo Book y el Videocurrículum, tanto en castellano como en inglés, con el fin de potenciar el marketing y la comunicación en el profesional del ámbito audiovisual. Asimismo, esta iniciativa se presenta como un método de enseñanzaaprendizaje novedoso para los alumnos en el área de la orientación laboral y el emprendimiento de proyectos, plasmando de manera visual y atractiva la compilación de trabajos, competencias y habilidades que los alumnos han ido adquiriendo a lo largo de su formación y bagaje profesional. Acorde con ello, se destaca la capacidad por parte de los alumnos de demostrar unos resultados altamente satisfactorios en el reconocimiento de las competencias específicas aprendidas. Este proyecto, asimismo, contribuye a fomentar las nuevas tecnologías y el trabajo con la plataforma virtual Blackboard, al permitir la divulgación de contenidos y facilitar que tanto docentes como alumnos puedan compartir el conocimiento. Finalmente, se destaca la importancia de trabajar de manera transversal con diferentes módulos del ciclo formativo, con el objetivo de proporcionar la lógica y fundamentación adecuada al proceso en su conjunto.
\end{abstract}

Keywords: reel-videocurrículum, método de enseñanza-aprendizaje, TIC, marketing profesional.

\begin{abstract}
The video $\mathrm{CV}$ reel production project combines in one piece the resource of the Video Book and that of the video CV, both in Spanish and English, in order to enhance marketing and communication for audio-visual professionals. In addition, this initiative is presented as an innovative teaching and learning method for students in the area of career guidance and projects entrepreneurship, capturing in a visual
\end{abstract}


El Reel-Videocurrículum como estrategia para el fomento del marketing profesional.

Ángela María Sánchez Sánchez-Manjavacas, María Soledad Folgado Canelles, Antonia Madueño

Toribio, Amparo Martín Moret y Luis Valero Taverner.

and attractive way the compilation of assignments, skills and abilities that students have acquired throughout their training and professional background. Accordingly, the ability of the students to show highly satisfactory results in the recognition of the specific competences learned is highlighted. Moreover, this project also helps to promote new technologies and work with the virtual platform Blackboard by allowing the diffusion of content and facilitating that both teachers and students share knowledge. Finally, the importance of working transversally with different subjects in this training short cycle is emphasised with the aim of providing the appropriate logic and foundation to the process as a whole.

Keywords: video CV reel, teaching and learning methods, ICT, professional marketing.

\section{Introducción}

La realización del proyecto Reel-Videocurrículum significa la unión en una misma pieza del recurso del Video Book y el Videocurrículum. El objetivo principal estriba en potenciar el marketing profesional del alumnado, promoviendo la adquisición y el desarrollo de métodos de enseñanza-aprendizaje novedosos en el ámbito de la Realización de Proyectos Audiovisuales y Espectáculos.

Cabe subrayar que las TIC han llevado al nacimiento de nuevos enfoques y ambientes de aprendizaje que a su vez ha creado la necesidad de diseñar nuevas estrategias de enseñanza utilizando dichos recursos, pero no obstante, estas nuevas tecnologías, además de producir cambios en el proceso de enseñanza deben producir cambios en los procesos de aprendizaje y se deben evaluar diversos aspectos al momento de estructurar la información a impartir (González y Pérez, 2016; Ovando, 2018).

Esta iniciativa permite trabajar de forma innovadora el área de la orientación laboral y el emprendimiento de proyectos, plasmando de manera visual y atractiva la compilación de trabajos, competencias y habilidades que los alumnos/as van adquiriendo a lo largo de su formación y bagaje. Los alumnos/as cuentan, además, con la motivación de trabajar contenidos, que habitualmente consideran alejados de su sector o sus intereses, mediante herramientas y procesos más atractivas por el interés que su propio sector audiovisual les genera. En este sentido, se ensalza el principio motivacional en la docencia que afirma que aquello que nos interesa lo aprendemos mejor (Gallardo y Camacho, 2008). Del mismo modo, facilitará que los estudiantes puedan promocionar sus puntos fuertes, aptitudes y aspiraciones en el ámbito profesional, impulsando con ello una mayor proyección de futuro (Álvarez Martínez, et al., 2016). Y es que, este recurso promueve que el alumno se dé a conocer a nivel laboral, tanto por cuenta ajena (para formar parte de un equipo de trabajo dentro de una empresa), como por cuenta propia (impulsando un negocio). Asimismo, no debemos olvidar incluir en este trabajo la importancia del inglés como forma de expansión de conocimientos e incremento del valor añadido en el alumnado.

(cc) EY-NC-ND 2018, Universitat Politècnica de València

Congreso IN-RED (2018) 
Otro punto importante a destacar es la transversalidad de los diferentes módulos del curso presentes en el proyecto, aprovechando con ello las ventajas que ofrece la integración de los contenidos de "Empresa e Iniciativa Emprendedora"; "Inglés Técnico", "Procesos de Realización en Cine y Vídeo", "Realización del Montaje y Postproducción en Audiovisuales” y "Medios Técnicos Audiovisuales”.

En esta misma línea, el proyecto también integra la transversalidad en competencias básicas tales como la resolución de problemas, aprender a aprender, competencia digital, comunicación lingüística, sentido de la iniciativa y espíritu emprendedor o conciencia y expresiones culturales, las cuales permiten enseñar conocimientos de los módulos aquí referenciados con el objetivo de que el alumno/a alcance una formación integral al finalizar su etapa académica y que, del mismo modo, sea capaz de aplicar los conocimientos adquiridos a su vida real. De esta manera, el alumno reconocerá y controlará sus propios procesos de aprendizaje, ajustándolos en tiempo y demanda de actividades, hasta un aprendizaje bilingüe, autónomo y transversal.

Con todo, el proyecto aspira a proyectar los objetivos laborales y empresariales del alumno/a de forma internacional, necesitando tener en cuenta a tal efecto la multiculturalidad de un mercado laboral y empresarial global.

\section{Objetivos}

Como objetivos generales de la innovación desarrollada destacamos los siguientes:

1.- Analizar y utilizar los recursos y oportunidades de aprendizaje relacionados con la evolución científica, tecnológica y organizativa del sector y las tecnologías de la información y la comunicación, para mantener el espíritu de actualización y adaptarse a nuevas situaciones laborales y personales.

2.- Desarrollar la creatividad y el espíritu de innovación para responder a los retos que se presentan en los procesos y en la organización del trabajo y de la vida personal.

3.- Desarrollar técnicas de liderazgo, motivación, supervisión y comunicación en contextos de trabajo en grupo, para facilitar la organización y coordinación de equipos de trabajo.

4.- Aplicar estrategias y técnicas de comunicación, adaptándose a los contenidos que se van a transmitir, a la finalidad y a las características de los receptores, para asegurar la eficacia en los procesos de comunicación.

5.- Utilizar procedimientos relacionados con la cultura emprendedora, empresarial y de iniciativa profesional, para realizar la gestión básica de una pequeña empresa o emprender un trabajo.

Asimismo, y de manera más específica, resaltamos los siguientes objetivos generales de índole técnico en el campo profesional del alumnado destinatario:

1.- Aplicar los códigos expresivos, narrativos y comunicativos audiovisuales básicos de la expresión audiovisual. 
2.- Decidir y gestionar las necesidades y funciones de los equipamientos técnicos y materiales para determinar sus características en la realización del proyecto.

3.- Aplicar las técnicas de programación de la actividad y recursos, tanto humanos como materiales, para planificar el proceso de trabajo de realización del proyecto audiovisual.

4.- Aplicar técnicas narrativas y expresivas de planificación de secuencias y puesta en escena para la elaboración de la documentación técnica de realización de la grabación del proyecto audiovisual.

5.- Analizar y aplicar las técnicas de montaje idóneas en la consecución de los objetivos comunicativos, para realizar el montaje/edición y postproducción del proyecto.

6.- Planificar y coordinar las operaciones de preparación de materiales y efectos, para la realización del proceso de montaje/edición y postproducción del proyecto.

\section{Desarrollo de la innovación}

El Reel-Videocurrículum como proyecto de innovación se desarrolló en el contexto de la formación profesional, más concretamente en el curso 2016-2017, del ciclo formativo de grado superior de Realización de Proyectos Audiovisuales y Espectáculos.

Dado la importancia que tiene la adquisición de una base previa de conocimientos de los destinatarios en el área de estudio, el proyecto se llevó a cabo con los dieciocho alumnos de segundo curso del ciclo.

\subsection{Módulos implicados en la innovación:}

A continuación, se detallan los módulos del ciclo formativo que tuvieron una implicación en la realización de este proyecto, por orden cronológico de impartición, durante los meses de enero y febrero de 2017.

\subsubsection{Empresa e Iniciativa Emprendedora:}

Número de sesiones que comprende: 3 sesiones (9h lectivas).

Espacios utilizados: Aula de Apoyo de Fotografía y Aula Mac (CEPAB.- Centro de Producción Multimedia).

Materiales: Recursos de vídeo (ejemplos de formatos reel), documentos explicativos/bibliografía (apuntes proporcionados por la profesora, CV de los alumnos). Empresa e Iniciativa Emprendedora, editorial Paraninfo (Asensio y Vázquez, 2016), y Empresa e Iniciativa Emprendedora, editorial MacGrawHill (Salinas Sánchez, et al., 2015).

\section{Objetivos específicos:}

- Presentar una alternativa a la carta de presentación y al currículum vítae tradicional.

(cc) EY-NC-ND 2018, Universitat Politècnica de València

Congreso IN-RED (2018) 
- Desarrollar materiales de presentación de la vida laboral como mecanismo de promoción y comunicación.

- Potenciar la imagen del autoempleo y emprendimiento.

\section{Contenidos:}

- Vocabulario: Recursos específicos sobre la búsqueda de empleo y el emprendimiento.

- Redacción: Contenidos sobre el Currículum Vítae.

\subsubsection{Inglés técnico:}

Número de sesiones que comprende: 2 sesiones (4h lectivas).

Espacios utilizados: Aula de Apoyo de Fotografía.

Materiales: Recursos de vídeo y documentos explicativos/bibliografía (apuntes proporcionados por la profesora, páginas web especializadas en CV en lengua inglesa y Video CV en inglés, fichas para autocompletar). BBC website, Commercially Speaking (Irvine y Cadman, 1999), Business Vocabulary (Mascull, 2010), Presentations in English (Williams, 2008).

\section{Objetivos específicos:}

- Producir mensajes orales en lengua inglesa, en situaciones habituales del ámbito social y profesional de la empresa reconociendo y aplicación las normas propias de la lengua inglesa.

- Utilizar recursos, estructuras lingüísticas, y léxico básico relacionados con el ámbito laboral: currículum vitae en distintos modelos.

\section{Contenidos:}

- Vocabulario: Recursos y estructuras lingüísticas del ámbito laboral (tecnicismos y estructuras lingüísticas inglesas prototípicas del sector laboral y del marketing).

- Gramática: Condicionalidad. Diferentes formas de expresar futuro (II).

- Redacción: CV.

- Expresión Oral: Búsqueda de empleo. Video CV. La entrevista de trabajo.

\subsubsection{Medios Técnicos Audiovisuales:}

El módulo de Medios Técnicos Audiovisuales forma parte del primer curso del ciclo formativo. No obstante, es importante el apoyo y asesoramiento en la elección del material técnico necesario para ejecutar el Proyecto.

Número de sesiones que comprende: 1 sesión (2h lectivas).

Espacios utilizados: Aula de Apoyo de Fotografía y diferentes instalaciones del Centro de Producción Audiovisual (platós). 
Materiales: Recursos de vídeo y documentos explicativos/bibliografía (apuntes proporcionados por la profesora y manual del módulo Medio Técnicos Audiovisuales). Iluminación para cine y video (Brown, 2012), Televisión, realización y lenguaje audiovisual (Castillo, 2016), Tecnología básica del sonido (I yII) (Cuenca y Gómez, 2006), Manual básico de tecnología audiovisual (Martínez y Vila, 2004), Las lentes y sus aplicaciones (Ray, 2001).

\section{Objetivos específicos:}

- Seleccionar objetivos y sistemas ópticos de cámara de vídeo en función de las características de cada proyecto de grabación concreto.

- Seleccionar las distintas configuraciones de iluminación, tipos de focos, selección de filtros y elementos lumínicos para la resolución de una variada tipología de procesos audiovisuales.

- Concretar las prestaciones técnicas de captación de sonido, justificando el uso de diversos micrófonos y accesorios necesarios según las características funcionales y operativas de cada proyecto.

- $\quad$ Elaborar el listado de localizaciones posibles y estudio de posibilidades técnicas dependiendo si son interiores (Centro de Producción Audiovisual, salas de control, platós, etc.) o exteriores.

- Elegir el formato de grabación, aspecto de imagen y resolución de imagen.

\section{Contenidos:}

- $\quad$ Tipos de cámaras, objetivos y soportes a elegir.

- $\quad$ Tipo de iluminación y filtros.

- $\quad$ Sonido, uso de micrófonos, capas de audio y video, y elección del formato.

- Localización para la grabación.

\subsubsection{Procesos de Realización en Cine y Vídeo:}

Número de sesiones que comprende: 4 sesiones (6h lectivas).

Espacios utilizados: Aula de Apoyo de Fotografía, aula de ordenadores Mac CEPAB, Instalaciones CEPAB (platós, estudios y salas de montaje y protools).

Materiales: Recursos de vídeo, apuntes proporcionados por la profesora, páginas web especializadas en CV y recursos técnicos para la grabación de los proyectos (cámaras, micrófonos, equipos de iluminación, trípodes, monitores, etc.). Manual del productor audiovisual (Martínez y Fernández, 2010), La producción cinematográfica (Mollá Furió, 2012), Cortos en cine y video (Irving y Rea, 2010).

\section{Objetivos específicos:}

- Planificar la realización de un vídeo-currículum que presente los trabajos realizados por los alumnos, así como sus aptitudes individuales. 
- Pensar y diseñar un estilo de realización propio e individual de acuerdo con el trabajo que se va a hacer sin perder los objetivos del mismo, así como, elegir el espacio o los espacios donde se va a llevar a cabo la grabación.

- Elegir y utilizar los recursos técnicos pertinentes para su grabación. Tipo de cámara, soportes de grabación, iluminación y microfonía.

- Realizar las labores de preparación del set, iluminación, toma de sonido, selección de encuadres, etc.

- Realizar la grabación audiovisual técnicamente correcta para su posterior edición en las clases correspondientes al módulo de Montaje y Postproducción.

\section{Contenidos:}

- Desarrollo de la idea del proyecto. Guión a dos columnas.

- Listado de recursos técnicos y humanos para la grabación.

- Gestión y reserva del espacio o espacios a usar en la grabación.

- Plan de rodaje.

- $\quad$ Orden de rodaje.

\subsubsection{Realización del Montaje y Postproducción en Audiovisuales:}

Número de sesiones que comprende: 2 sesiones (7h lectivas).

Espacios utilizados: Aula de Apoyo de Fotografía, aula de ordenadores Mac CEPAB, Instalaciones CEPAB (platós, estudios y salas de montaje y protools).

Materiales: Recursos de vídeo, apuntes proporcionados por la profesora, páginas web especializadas en CV y recursos técnicos para la grabación de los proyectos (cámaras, micrófonos, equipos de iluminación, trípodes, monitores, etc.). Postproducción en Alta Definición (Browne, 2008), Edición de vídeo con Avid (Moreno Lacalle, 2007), Avid: edición de video (Kauffmann, 2010), Manuales imprescindibles (Martínez y Panadero, 2013; Moreno Lacalle, 2013).

\section{Objetivos específicos:}

- Editar los reels de presentación bajo unas premisas orientadas a que cada uno de los alumnos siguiese los criterios de creatividad particulares.

- Repasar y poner en práctica todo lo aprendido durante el curso en el modulo.

\section{Contenidos:}

- Edición básica y avanzada.

- Etalonaje.

- Sonorización.

- Trabajo con máscaras y varias capas de vídeo.

- Efectos audiovisuales.

- Exportación y formatos. 
El Reel-Videocurrículum como estrategia para el fomento del marketing profesional.

Ángela María Sánchez Sánchez-Manjavacas, María Soledad Folgado Canelles, Antonia Madueño

Toribio, Amparo Martín Moret y Luis Valero Taverner.

\subsection{Detalle de acciones realizadas:}

A continuación, se detalla la estrutura básica de las sesiones realizadas en cada uno de los módulos, así como las acciones específicas llevadas a cabo en el desarrollo del proyecto Reel Videocurrículum.

\subsubsection{Empresa e Iniciativa Emprendedora:}

$1^{\text {a }}$ sesión. 26 de enero: Concreción de la idea del proyecto general. Relación del proyecto con el marketing y la búsqueda de empleo. Análisis del Currículum Vítae y los trabajos audiovisuales previos realizados por los alumnos.

$2^{a}$ sesión. 2 de febrero: Selección de contenidos para desarrollar el Reel-VideoCV. Concreción de imágenes, secuencias de proyectos y trabajos realizados con anterioridad (tanto en el ciclo formativo como a nivel particular/amateur). Concreción de las aptitudes a resaltar relacionadas con el trabajo en el ámbito de la realización audiovisual. Concreción de la información a destacar en la grabación de la entrevista (relacionada con la experiencia y formación alcanzada). Selección de la música para el Reel-VideoCV (incluyendo el nombre de las canciones y los autores en los títulos).

$3^{a}$ sesión. 9 de febrero: Desarrollo de la estructura cronológica del contenido del ReelVideoCV. Ordenación de la información en forma de secuencias y tiempo utilizado para cada recurso. Presentación y recogida del documento.

\subsubsection{Inglés Técnico:}

$1^{\text {a }}$ sesión. 7 de febrero: Presentación de vocabulario de los tecnicismos y estructuras lingüísticas inglesas prototípicas del sector laboral y del marketing. Actividades de expresión oral para practicar la teoría presentada.

$2^{a}$ sesión. 14 de febrero: Presentación de ejemplos de perfiles profesionales y proyectos empresariales en lengua inglesa en diversos formatos y plataformas. Elaboración por parte de los alumnos/as de una compilación de datos procedentes de sus perfiles profesionales y sus proyectos empresariales en lengua inglesa para adaptarlos al guión de sus respectivos Reel- Video CV.

\subsubsection{Medios Técnicos Audiovisuales:}

$1^{\text {a }}$ sesión. 7 de febrero: en la sesión de orientación destinada en este módulo se generó un feedback entre docente y alumnos para intercambiar opiniones sobre diferentes elementos técnicos, en función de la tormenta de ideas que cada alumno había desarrollado para su proyecto.

Resaltamos en mayor medida los siguientes aspectos: análisis de las necesidades y funciones de los equipamientos técnicos y materiales; toma de decisiones sobre el equipamiento de cámaras, iluminación y sonido de forma fundamentada y, consulta de

(cc) EY-NC-ND 2018, Universitat Politècnica de València

Congreso IN-RED (2018) 
bibliografía que pudiese servirles de guía. Este último hecho resultó especialmente positivo ya que contribuyó a que los alumnos recurriesen a los libros como fuente de formación y ayuda, y no como un mero material para examen.

\subsubsection{Procesos basicos de Realización en Cine y Vídeo:}

$\mathbf{1}^{\text {a }}$ sesión. 7 de febrero: Visionado y análisis de las diferentes opciones de vídeocurrículums que existen en el mercado. Feedback. Desarrollo de la idea.

$2^{\text {a }}$ sesión. 9 de febrero: Presentación idea individual y preproducción proyecto. Elaboración de guiones. Formación de grupos de grabación por localizaciones, de forma que los alumnos que coincidan en el mismo espacio de grabación, se ayudarán unos a otros en las labores de grabación e iluminación. Organización del orden de rodaje.

$3^{a}$ sesión. 14 de febrero: Grabación individual de los alumnos presentando sus trabajos y cualidades así como las imágenes de recurso de ellos trabajando en el control de realización, con las cámaras, en las salas de montaje, etc.

$4^{a}$ sesión. 16 febrero: Grabación individual de los alumnos presentando sus trabajos y cualidades así como las imágenes de recurso de ellos trabajando en el control de realización, con las cámaras, en las salas de montaje, etc. Ingesta de archivos en el servidor y creación de proyectos para las labores de montaje en las horas lectivas que corresponden a la asignatura de Montaje y Postproducción.

\subsubsection{Realización del Montaje y Postproducción en Audiovisuales:}

$\mathbf{1}^{\text {a }}$ sesión. 17 febrero: Edición de los propios reels de presentación bajo premisas claras orientadas a que cada uno de los alumnus llevase a cabo el trabajo acorde con sus propios criterios de creatividad.

$2^{a}$ sesión. 24 febrero: Continuación del desarrollo del proceso de edición con utilización del sistema AVID de edición y sistema AFTER EFFECTS, para terminar ofreciendo un acabado más profesional a sus trabajos.

\section{Resultados}

Desde el conjunto de módulos estudiados en el segundo curso del ciclo formativo de grado superior en Realización de Proyectos Audiovisuales y Espectáculos, determiner que se ha innovado bajo el punto de vista del trabajo transversal que los alumnos han llevado a cabo con el proyecto audiovisual. Su finalidad estriba, por tanto, en desarrollar un vídeo que será utilizado en el presente y/o futuro como herramienta propia del mismo alumno a la hora de encontrar trabajo y dar a conocer de manera innovadora sus capacidades y habilidades adquiridas en el ámbito. 
El Reel-Videocurrículum como estrategia para el fomento del marketing profesional.

Ángela María Sánchez Sánchez-Manjavacas, María Soledad Folgado Canelles, Antonia Madueño

Toribio, Amparo Martín Moret y Luis Valero Taverner.

Al hilo de esta idea, consideramos que el mejor o peor resultado del trabajo puede influir directamente en el uso que el alumno/a quiera hacer de esta herramienta, mucho más allá de la nota académica. En este sentido, desde la totalidad de módulos, los docentes han orientado técnicamente para enfocar este trabajo como una herramienta esencial con la que destacar frente a otros posibles candidatos a un puesto laboral, al presenter de manera más atractiva y visual su bagaje formative y profesional.

Asimismo, determinamos que el hecho de tratarse de un caso práctico real donde los propios estudiantes son los primeros beneficiarios de un buen resultado, supone una motivación añadida para el aprendizaje de los contenidos teórico-prácticos de los módulos. $\mathrm{Y}$ es que, se aprecia un notable aumento de la curiosidad por los contenidos trabajados, fomentando que en numerosas ocasiones los mismos/as alumnos/as sean quienes soliciten más recursos y materiales relacionados con aquellos integrados en el proyecto.

Se observa que, tras las dinámicas de las actividades aplicadas a la preparación, ensayo y realización del Reel-Videocurrículumv, los alumnus son capaces de recorder los procedimientos necesarios en cada uno de los módulos, interiorizando de manera más eficaz el contenido impartido con anterioridad en el aula, así como trabajar con el vocabulario técnico, las estructuras y expresiones técnicas del sector con mayo facilidad (tanto en lengua española como inglesa).

La interacción con otros módulos del mismo ciclo, a su vez, contribuye a que los alumnos no perciban estos como compartimentos estancos, sino que aprecien que lo aprendido en cada uno de ellos sirve para alcanzar un fin común, que es el de su formación profesional integral, en general, y la realización del proyecto, en particular.

A continuación, se destacan imágenes utilizadas en cada uno de los vídeos. En total, dieciocho proyectos de una duración de entre un minuto y dos minutos, cada uno de ellos.

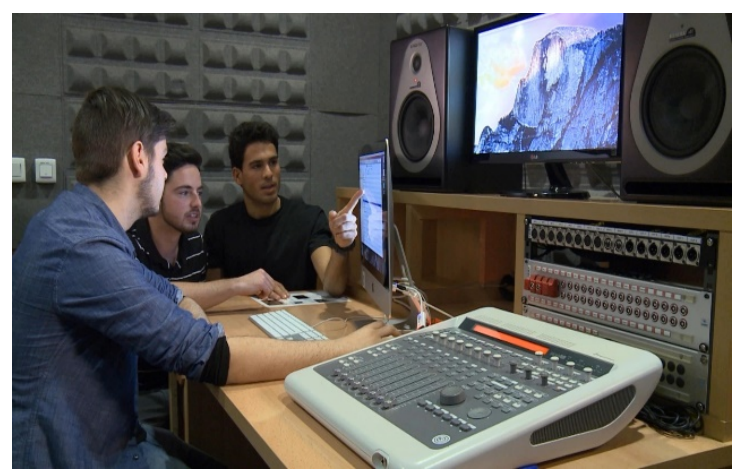

Fig. 1 Trabajo conjunto en control de realización 
El Reel-Videocurrículum como estrategia para el fomento del marketing profesional Ángela $M^{a}$ Sánchez Sánchez-Manjavacas, $M^{a}$ Soledad Folgado Canelles, Antonia Madueño Toribio, Amparo Martín Moret y Luis Valero Taverner

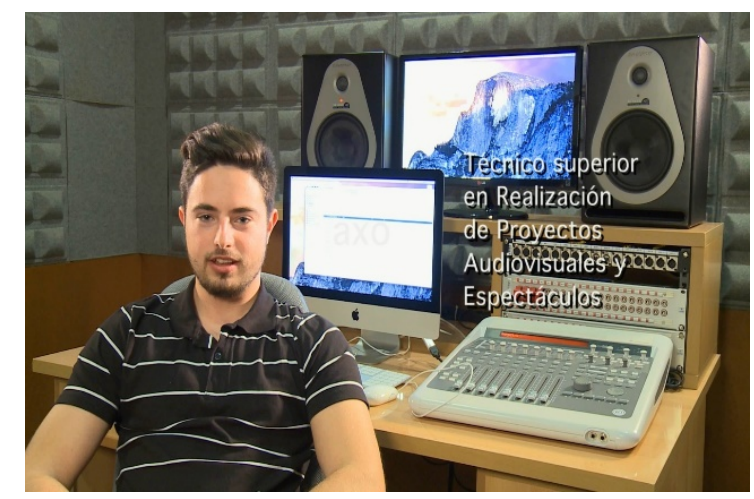

Fig. 2 Imagen con contenido específico a destacar I

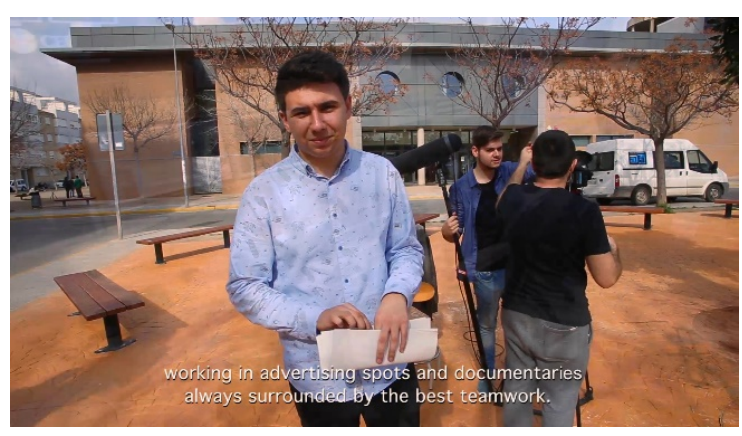

Fig. 3 Imagen con contenido específico en inglés a destacar

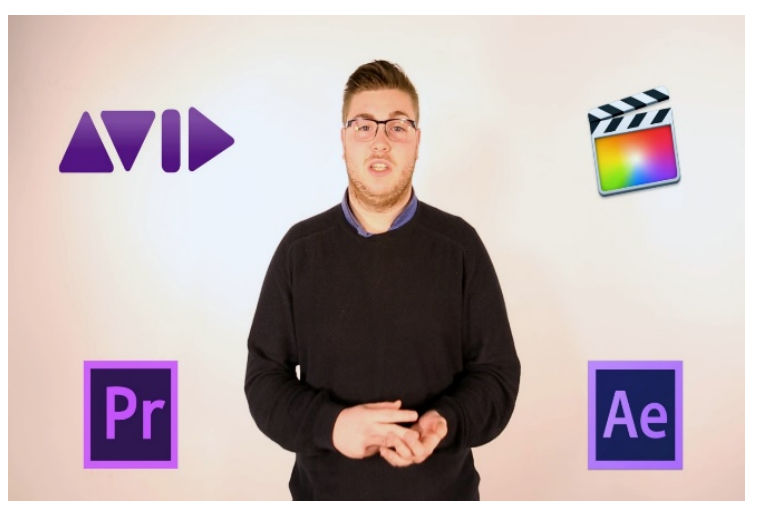

Fig. 4 Imagen con contenido específico a destacar II

(cc) EY-Nc-ND 2018, Universitat Politècnica de València

Congreso In-Red (2018) 
El Reel-Videocurrículum como estrategia para el fomento del marketing profesional.

Ángela María Sánchez Sánchez-Manjavacas, María Soledad Folgado Canelles, Antonia Madueño

Toribio, Amparo Martín Moret y Luis Valero Taverner.

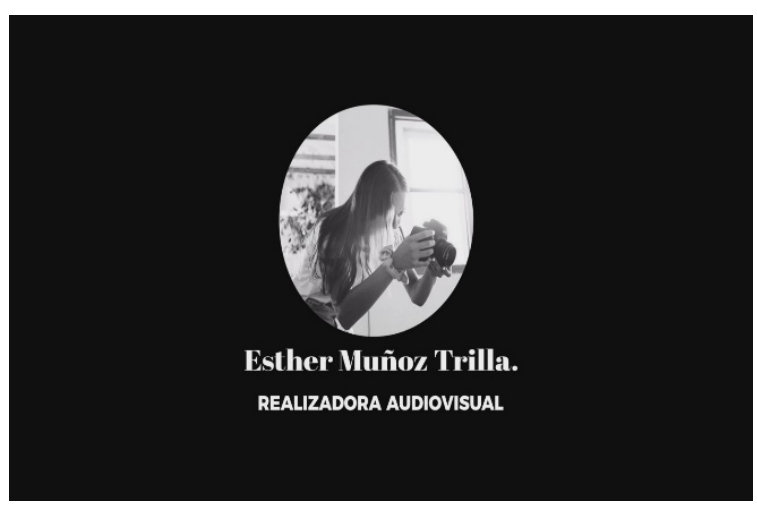

Fig. 5 Imagen con contenido específico a destacar III

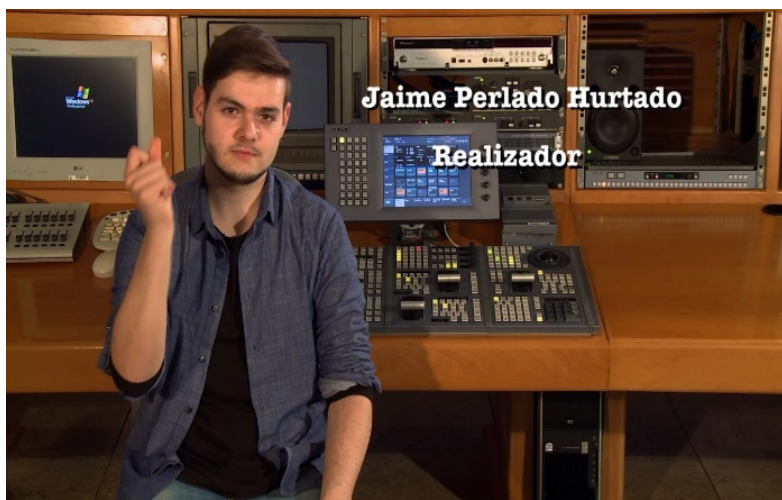

Fig. 6 Imagen con contenido específico a destacar IV

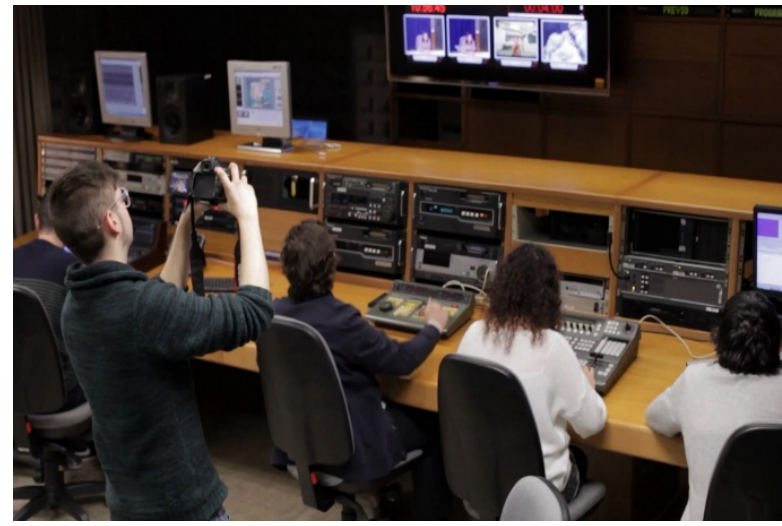

Fig. 7 Trabajo conjunto en control I

(cc) BY-NC-ND 2018, Universitat Politècnica de València

Congreso IN-RED (2018) 


\section{Conclusiones}

Es de suma importancia la elaboración de esta innovadora herramienta que permite al alumno distinguirse de los demás por sus habilidades sociales, creativas y profesionales. Sin duda, la realización del proyecto Reel-Videocurrículum sirve a los estudiantes de carta de presentación novedosa a la hora de su incorporación en el mercado laboral (Álvarez Martínez, et al., 2016).

De este modo, los alumnos/as han comprobado en primera persona que el trabajo desarrollado por medio del contenido de la actividad les ha proporcionado un resultado que podrán utilizar a corto plazo con el objetivo real de buscar empleo en el sector audiovisual no solo a nivel nacional, sino internacional. Este aspecto genera en ellos/as una certeza inmediata de utilidad del conocimiento adquirido.

Así pues, la realización de este proyecto implica resaltar las posibilidades de expansión de los protagonistas de dichos vídeos, al combinar los contenidos con el inglés como idioma fundamental en un contexto pragmático real (Gallardo y Camacho, 2008). De esta manera, incrementan su valor añadido y polivalencia ante un mercado laboral cada vez más competitivo (González y Pérez, 2016). Y es que, la enseñanza moderna de lenguas extranjeras y sus variedades específicas, como en este caso el inglés técnico para la comunicación audiovisual, exige la integración de sus elementos lingüísticos y sus habilidades comunicativas dentro del ámbito sociolaboral, siendo posible a través del proyecto de forma natural y fluida.

La posibilidad para los y las estudiantes de trabajar los contenidos de los diferentes módulos haciendo lo que realmente les motiva y les genera curiosidad, como es la preproducción, producción y postproducción de vídeos, ha garantizado que incrementaran su esfuerzo y dedicación para conseguir los objetivos de aprendizaje, sin apenas estímulo externo por parte de la docente. Constatamos, por tanto, una remarcable y positiva influencia de la motivación extrínseca.

Este proyecto, asimismo, contribuye a fomentar las nuevas tecnologías y el desarrollo de la plataforma virtual Blackboard (como herramienta de trabajo y comunicación entre docentes y alumnos utilizado por el ISEP CEU CV), al permitir la divulgación de contenidos y facilitar que todos los protagonistas del proyecto puedan compartir el conocimiento. Por otra parte, y de manera complementaria, el uso de la plataforma permite controlar el proceso, no sólo de manera presencial, sino también on-line, consiguiendo con ello mayor capacidad de reacción y respuesta en el proceso de enseñanza-aprendizaje.

No debemos olvidar la colaboración entre los diferentes módulos y contenidos que conforman el ciclo formativo, por lo que el complemento de la transversalidad ha estado muy presente en los profesionales docentes. Así pues, de manera cronológica, se han ido combinando y organizando los módulos a impartir en el segundo curso del ciclo, proporcionando una lógica y fundamentación a la totalidad del proceso.

Por todo ello, se destaca la capacidad por parte de los alumnos de demostrar, tras la finalización del proceso de aprendizaje, unos resultados altamente satisfactorios y cuantificables en las competencias específicas citadas a lo largo de este trabajo. Y es que, 
en un solo proyecto los alumnos han puesto en práctica todos y cada uno de los temas impartidos a lo largo del curso (especialmente en las materias de índole más técnico).

Sin embargo, esta labor también presenta ciertas limitaciones al respecto como es la no obligatoriedad de subir los contenidos a los diferentes portales de Internet, como pueden ser Youtube y Vimeo, ni a las distintas redes sociales, como Facebook e Instagram, entre otras. Este hecho dificulta ciertamente la medición del impacto de los trabajos en el ámbito sociolaboral.

Por ello, y como futuras líneas de investigación, debemos considerar la posibilidad de hacer un mayor seguimiento sobre el porcentaje de inserción laboral de los alumnos/as una vez finalizado el ciclo formativo, valorando en la medida de lo posible la repercusión que la herramienta del Reel-Videocurrículum ha tenido en los procesos de reclutamiento de las empresas. No obstante, para ello, se entiende fundamental que los y las estudiantes puedan suban dichos materiales a los diferentes portales y redes sociales, con el fin de generar mayor impacto en su labor.

\section{Referencias}

ÁLVAREZ MARTÍNEZ, J.C.; HERRÁEZ VIDAL, P. y PRIETO GARCÍA, M.A. (2016). Formación y Orientación Laboral. Madrid: MacMillan Education.

ASENSIO DEL ARCO, E. y VÁZQUEZ BLÖMER, B. (2016). Empresa e Iniciativa Emprendedora. $3^{a}$ edición actualizada 2016. Madrid: Paraninfo ciclos formativos.

Portal oficial de BBC. Get that Job.

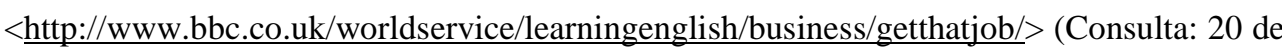
marzo de 2017)

BROWN, B. (2012). Iluminación para cine y video. Andoain: Ed. Focal Press.

BROWNE, S.E. (2008). Postproducción en Alta Definición. Andoain: Ed. Escuela de Cine y Vídeo.

CASTILLO, J.M. (2016). Televisión, realización y lenguaje audiovisual. Madrid: Ed. Instituto RTVE.

CUENCA, I. y GÓMEZ, E. (2006). Tecnología básica del sonido (I y II). Madrid: Editorial Paraninfo.

GALLARDO, P. y CAMACHO, K.J.M. (2008). La motivación y el aprendizaje en educación. Wanceulen Educación.

GONZÁLEZ ACEDO, J.C. y PÉREZ AROCA, R. (2016). Formación y Orientación Laboral. Madrid: Paraninfo Ciclos Formativos.

IRVINE, M. y CADMAN, M. (1999). Commercially Speaking. Oxford: Oxford University Press. 
K. IRVING, D. y W. REA, P. (2010). Cortos en cine y video. Producción y dirección. Barcelona: Ediciones Omega, S.A.

KAUFFMANN, S. (2010). Edición de video con avid media composer. Barcelona: Anaya multimedia.

MARTÍNEZ ABADÍA, J. y VILA FUMÁS, P. (2004). Manual básico de tecnología audiovisual y técnicas de creación, emisión y difusión de contenidos. Madrid: Editorial Paidós.

MARTÍNEZ, J. y FERNÁNDEZ, F. (2010). Manual del productor audiovisual. Barcelona: Editorial UOC.

MARTÍNEZ SOTILLOS, M. y PANADERO RIOL, J.C. (2013). Manual imprescindible After Effects CS6. Madrid: Anaya Multimedia.

MASCULL, B. (2010). Business Vocabulary in Use Intermediate with Answers. Cambridge: Cambridge University Press.

MOLLÁ FURIÓ, D. (2012). La producción cinematográfica. Las fases de la creación de un largometraje. Barcelona: Editorial UOC.

MORENO LACALLE, R. (2007). Avid: Edición de video. Barcelona: Anaya multimedia.

MORENO LACALLE, R. (2013). Manuales imprescindibles: Avid Media Composer. Barcelona: Anaya multimedia.

RAY, S. (2001). Las lentes y sus aplicaciones. Andoain: Ed. Escuela de cine y video.

SALINAS SÁNCHEZ, J.M., GÁNDARA MARTÍNEZ, J. y ALONSO SÁNCHEZ, A. (2015). Empresa e Iniciativa Emprendedora. Madrid: McGrawHill Education.

WILLIAMS, E.J. (2008). Presentations in English: find your voice as a presenter. Madrid: MacMillan. 